\title{
Compact pulse repetition rate multiplication scheme using micro ring resonator
}

\author{
Ji, Hua; Pu, Minhao; Galili, Michael; Oxenløwe, Leif Katsuo; Jeppesen, Palle
}

\section{Published in:}

Conference abstract series, CLEO/Europe - EQEC

Link to article, DOI:

10.1109/CLEOE-EQEC.2009.5196371

Publication date:

2009

Document Version

Publisher's PDF, also known as Version of record

Link back to DTU Orbit

Citation (APA):

Ji, H., Pu, M., Galili, M., Oxenløwe, L. K., \& Jeppesen, P. (2009). Compact pulse repetition rate multiplication scheme using micro ring resonator. In Conference abstract series, CLEO/Europe - EQEC (pp. 1-1). IEEE. https://doi.org/10.1109/CLEOE-EQEC.2009.5196371

\section{General rights}

Copyright and moral rights for the publications made accessible in the public portal are retained by the authors and/or other copyright owners and it is a condition of accessing publications that users recognise and abide by the legal requirements associated with these rights.

- Users may download and print one copy of any publication from the public portal for the purpose of private study or research.

- You may not further distribute the material or use it for any profit-making activity or commercial gain

- You may freely distribute the URL identifying the publication in the public portal 


\title{
Compact Pulse Repetition Rate Multiplication Scheme Using Micro Ring Resonator
}

\author{
Hua Ji, Minhao Pu, Michael Galili, Leif K. Oxenlowe, Palle Jeppesen \\ DTU Fotonik, Department of Photonics Engineering, Technical University of Denmark, DK-2800 Lyngby, Denmark
}

High repetition rate stable short pulse sources play an important role in high speed optical communication systems. Besides developing a short pulse laser with very high fundamental repetition rate, the high repetition rate pulse train can also be obtained using various optical multiplication techniques, based on a Fabry-Pérot filter [1] or a fiber Bragg grating [2], for example. A more stable system may be achievable using an integrated component for multiplication. In this paper, a silicon-on-insulator (SOI) micro ring resonator with free spectral range (FSR) of $40.9 \mathrm{GHz}$ at $1550 \mathrm{~nm}$ is used as a filter to obtain a $40 \mathrm{GHz}$ pulse train. This device is compact and offers stable filtering characteristics.

The experimental setup of the pulse rate multiplier is shown in Fig. 1 (a). A tunable mode-locked laser (TMLL) is used to generate a pulse train at desired central wavelength and repetition rate. In this experiment, the central wavelength is at $1550 \mathrm{~nm}$ and the repetition rate is adjusted to be one quarter of the FSR of the micro ring resonator. The extinction ratio of the ring resonator is $27 \mathrm{~dB}$ and the $3 \mathrm{~dB}$ bandwidth is $0.014 \mathrm{~nm}$ which corresponds to a quality factor of $\sim 110000$. The micro ring resonator is sensitive to polarization and has $24 \mathrm{~dB}$ insertion loss, at the resonances. The loss includes fiber to waveguide coupling loss and resonator loss. The polarization controller and EDFA are used to ensure quasi-transverse magnetic (TM) mode and sufficient signal power into the resonator.

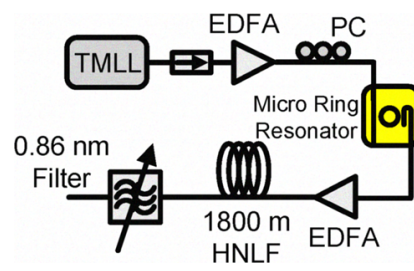

(a)

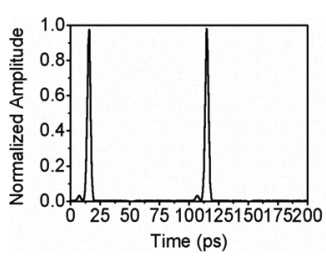

(b)

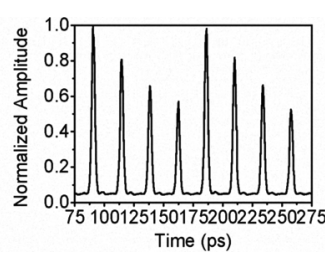

(c)

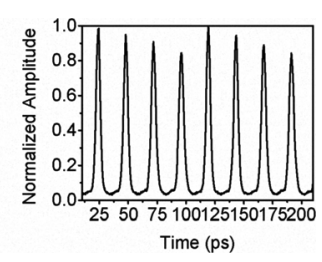

(d)

Fig. 1 (a) $40 \mathrm{GHz}$ pulse multiplication setup (b) Original $10 \mathrm{GHz}$ pulse train (c) $40 \mathrm{GHz}$ pulse train before equalizer (d) Final $40 \mathrm{GHz}$ pulse train after equalizer

The $10.29 \mathrm{GHz}$ pulse train at $1550 \mathrm{~nm}$ from the TMLL (Fig. 1 (b)) with pulse width $2.98 \mathrm{ps}$ is successfully multiplied to $41 \mathrm{GHz}$ pulse train (Fig. 1 (c)) after the micro ring resonator. The pulse width is broadened to 3.12 ps, an increase smaller than $5 \%$. However, the multiplied pulse train suffers from a variation of pulse power which can be seen from the temporal trace (Fig. 1 (c)). The amplitude modulation depth is about $3 \mathrm{~dB}$. This is caused by the coupling loss between ring and waveguides and the roundtrip propagation loss in the ring. Therefore the amplitude modulation depth can be decreased by reducing the coupling ratio and improving in fabrication process. To obtain a homogeneous pulse train, an equalizer relying on spectral broadening and optical filtering [3] is added after the repetition rate multiplier (Fig.1 (a)). The multiplied pulse train is sent through $1800 \mathrm{~m}$ highly non-linear fiber and a $0.86 \mathrm{~nm}$ FWHM narrow band pass filter. When the input average power into the equalizer is high enough $(30 \mathrm{dBm})$, the variation in pulse power can be decreased. The amplitude modulation depth is reduced from $3 \mathrm{~dB}$ to $0.7 \mathrm{~dB}$ by use of the equalizer as shown in Fig. 1 (d). The pulse width is broadened to $4.21 \mathrm{ps}$ due to the narrower spectrum induced by the band pass filter. By tuning the input signal repetition rate, it is also experimentally demonstrated that the micro ring resonator can tolerate about $50 \mathrm{MHz}$ mismatch between one quarter of its FSR and the input signal repetition rate. This means that the scheme is tolerant towards changes in input frequency despite the fixed FSR offered by the ring resonator. Clean pulse trains can still be obtained, however the pulse width is broadened due to the mismatch filtering resulting in a narrower optical spectrum. In the tolerant range of the micro ring resonator, the equalizer works equally effectively. The optimum amplitude modulation depth is $0.7 \mathrm{~dB}$ at different input repetition rates in the range of $10.19 \mathrm{GHz}-10.29 \mathrm{GHz}$, around one quarter of the FSR of the micro ring resonator $(10.23 \mathrm{GHz})$.

In conclusion, the scheme based on silicon-on-insulator micro ring resonator is compact and frequency tolerant and stable for pulse repetition rate multiplication.

\section{References}

[1] K.Yiannopoulos, K. Vyrsokinos, E. kehayas, N. Pleros, K. Vlachos, H. Avramopoulos and G. Guekos, "Rate Multiplication by DoublePassing Fabry-Perot Filtering", Photonics Technology Letters, IEEE 15, 1294-1296 (2003).

[2] P. Petropoulos, M.Ibsen, M.N.Zervas, and D.J. Richardson, "Generation of a $40-\mathrm{GHz}$ pulse stream by pulse multiplication with a sampled fiber Bragg grating," Opt. Lett. 25, 521-523 (2000).

[3] P.V. Mamyshev, "All-optical data regeneration based on self-phase modulation effect", ECOC 1998, pp 475-476, 1998 